\title{
Frequency Domain Approach to De-Noise the CN Tower Lightning Current Derivative Signal and Its Parameters Calculations
}

\author{
M.J. Islam and A.M. Hussein
}

\begin{abstract}
The Canadian National (CN) Tower is a transmission tower and it is not unexpected that recorded lightning current signals be corrupted by noise. The existence of noise may affect the calculation of current waveform parameters (current peak, $\mathbf{1 0 - 9 0 \%}$ risetime to current peak, maximum steepness, and pulse width at half value of current peak). To determine accurate statistics of current waveform parameters, the interfering noise must be removed. In this paper, a Short Term Fourier Transform (STFT)-based Spectral Subtraction method is developed to de-noise the lightning current derivative signal measured at the $\mathrm{CN}$ Tower. In order to evaluate the proposed de-noising method, a simulated current derivative waveform is used after being artificially distorted by a noise signal measured at the CN Tower in the absence of lightning. The de-noised waveform proved to be very close to the original simulated waveform. The STFT-based Spectral Subtraction method is then applied successfully to de-noise the lightning current derivative signal recorded at the $\mathrm{CN}$ Tower. A signal peak-to-noise peak ratio (SPNPR) of the lightning current signal is defined and calculated before and after the de-noising procedure.
\end{abstract}

Index Terms-CN Tower, Current Derivative Signal, Spectral Subtraction Method

\section{INTRODUCTION}

Lightning is one of the fascinating events of nature [1]. It is observed that tall structures receive more lightning strikes than plain ground. Traditionally they are very useful in studying characteristics of lightning. The Toronto Canadian National (CN) Tower, with a height of $553 \mathrm{~m}$, is the tallest manmade freestanding structure in the world. While the local lightning flash density in Toronto area is about 2 flashes per square kilometer per year, the Tower usually receives many tens of direct strikes during a lightning season. For example, during the summer of 1991, the CN Tower was hit with 74 flashes, 24 of which occurred within 100 minutes in the early morning of July 7 . Therefore, the $\mathrm{CN}$ Tower presents one of the best sites in the world to study the lightning phenomenon [2,3]. Lightning strikes to the CN Tower have been monitored since 1978, two years after its erection [3]. Successful simultaneous measurements

Manuscript received on March 31, 2009.

M.J. Islam is a doctoral student in Electrical and Computer Engineering Department of University of Windsor, Windsor, ON. Canada.

A.M. Hussein is a Professor of Electrical and Computer Engineering Department of Ryerson University, Toronto, ON, Canada. of significant parameters of $\mathrm{CN}$ Tower lightning strikes have been performed since the summer of 1991 [2]. By the beginning of the summer of 1991, five measurement stations were operating to simultaneously measure seven of the most important lightning parameters [2].

The current derivative measurement station is one of the five measurement stations, and it is installed at the $\mathrm{CN}$ Tower. A 40-MHz Rogowski coil, placed at the 474-m above ground level (AGL), captures approximately $20 \%$ of the current derivative since it encircles one fifth of the Tower's steel structure. The coil is connected, via a tri-axial cable, to a 10-bit, 10-ns, computer controlled double channel digitizer with segmented memory (Tektronix 710A), presently placed at the 403-m AGL. The digitizer has two channels and it provides a 10-bit vertical resolution at $\pm 0.4 \%$ accuracy and $200 \mathrm{MHz}$ maximum sampling rate for a single channel operation or $100 \mathrm{MHz}$ maximum sampling rate for both channels. A typical $\mathrm{CN}$ Tower Lightning return-stroke current derivative waveform (di/dt) and its corresponding current waveform (obtained through time integration) are shown in Fig. 1.

\section{MOTIVATION}

From the waveforms shown in Figs. 1, it is obvious that the measured current derivative and the current waveform are affected by various types of noise. These are as follows:

\section{A. DC Offset}

There is a noticeable DC offset in the di/dt waveforms and this interference is projected as a noticeable ramp after integration (Fig. 1(b)).

\section{B. High-Frequency Noise}

This type of noise does not have much effect on waveforms with high peak values of di/dt. It does, however, make the current derivative waveform shape unclear.

\section{Low-Frequency Noise around $100 \mathrm{kHz}$}

This interfering noise oscillating around $100 \mathrm{kHz}$ is normally slow in comparison with fast-rising current waveforms. Nevertheless, with this interference present, it is hard to calculate the current waveform parameters (peak, maximum steepness and $10 \%$ - $90 \%$ risetime) $[4,5]$.

\section{Reflections}

The discontinuities of the tower's structure cause several reflections when the lightning current wave propagates through the Tower [6]. 
Because of the existence of these kinds of noise, there have been serious limitations concerning the use of the $\mathrm{CN}$ Tower

current data captured during more than one decade

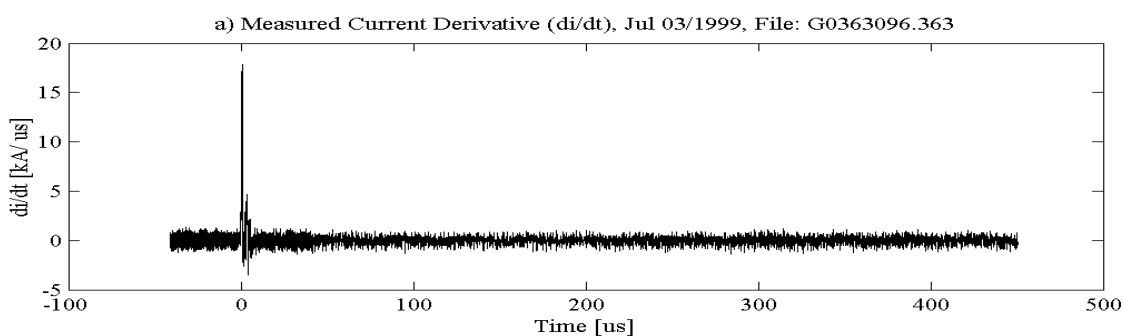

b) Current Waveform from Measured Current Derivative (di/dt), File: G0363096.363

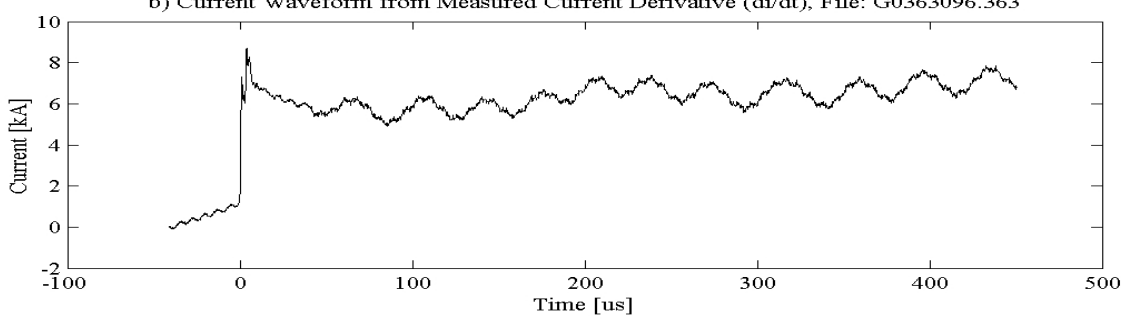

Fig. 1: A typical CN Tower lightning current derivative signal and its numerical integration (the current)

(1991-2003). In order to derive statistics concerning the lightning current waveform parameters, these parameters must be accurately determined. Cumulative statistics based on extensive data and accurate current waveform parameters are needed to help in the establishment of more sophisticated protective measures against lightning hazards. This major objective cannot be realized without de-noising the measured current signals.

\section{STATE-OF-THE ART}

The lightning current waveform contains a broad spectrum of frequencies which makes it very difficult to eliminate the noise without losing part of the lightning signal itself. Previous attempts to de-noise $\mathrm{CN}$ Tower lightning current signals have not yielded the satisfactory results.

The source of the low-frequency noise (around $100 \mathrm{kHz}$ ) is unknown and the source of the high-frequency noise is, at least partially, due to the broadcast antennas. Among different types of interference, DC offset is easy to remove by subtracting the average of the pre-stroke portion of the captured current derivative signal.

The high-frequency noise is practically minimized when the numerical integration of the recorded current derivative signal is performed to determine the current waveform. However, the existence of the high-frequency noise may influence the calculation of the maximum current wavefront steepness which is determined from the measured current derivative signal (Fig. 1). The low-frequency noise is difficult to remove using existing software filters because of its frequency modulated nature which lies within the wideband frequency response of the lightning current. So a special attention has been given to the removal of the low-frequency noise, oscillating around $100 \mathrm{kHz}$, in order to accurately extract the lightning current waveform parameters. Interference due to reflections is basically dependent on the structural discontinues of the Tower and it is possible to remove it using the transmission line model of the Tower.

In order to remove the interference from the lightning current signal, the following methods have been tried:

19) Adaptive filtering technique [7] has been tried with limited success to de-noise the low-frequency components, because the proposed algorithm is more suitable for signals of unlimited lengths. For signals of unlimited length, no difficulty is encountered in estimating and eliminating the interference; in such cases, the algorithm has enough time to identify the interference. However, signals with limited length may be affected by unidentified interferences of short duration, like $\mathrm{CN}$ Tower lightning current signals. In such cases, the algorithm loses its effectiveness in eliminating the noise due to the fact that it lacks enough information for proper identification of the noise.

20) A technique [8] for de-noising the CN Tower lightning current signal by modifying its Fast Fourier Transform was defined. The success of that method was limited, because some part of the original signal is removed that affects the calculation.

It is obvious from the above discussed methods that the success has been limited and a new method must be sought to specially de-noise the low-frequency noise components around $100 \mathrm{kHz}$.

\section{SPECTRAL SUBTRACTION METHOD}

A stand-alone noise suppression algorithm called STFT-based Spectral Subtraction can be adapted from [9, 10, 11]. It is assumed that the background noise is added to the pure signal, the background noise environment remains locally stationary to the degree that the expected value of spectral magnitude prior to signal activity equals its expected value during signal activity and significant noise reduction is possible by removing the effect of noise spectrum.

\section{E. Heidler Model Function}

Heidler model function [12] is a simulation of a lightning current signal. It is given by, 


$$
\begin{gathered}
i(t)=\frac{I_{0}}{2 \alpha}\left[\frac{\left(t / \tau_{1}\right)^{k}}{1+\left(t / \tau_{1}\right)^{k}} e^{-t / \tau_{2}}+\frac{\left(t / \tau_{3}\right)^{k}}{1+\left(t / \tau_{3}\right)^{k}} e^{-t / \tau_{4}}\right] \\
\text { Where } \alpha=0.9 \\
\tau_{4}=5 \mathrm{~ms} \\
\tau_{1}=\tau_{3}=0.23 \mu s \quad \mathrm{k}=4 \\
\tau_{2}=5 \quad \mu s \quad I_{0}=10 \mathrm{kA} \text { (Current Peak) }
\end{gathered}
$$

In order to simulate a current derivative waveform, the Heidler model function is differentiated numerically and artificially distorted by a noise signal measured at $\mathrm{CN}$ Tower in the absence of lightning. It is assumed that a similar noise is embedded in the CN Tower lightning current derivative signal. The noise signal measured at $\mathrm{CN}$ Tower in the absence of lightning and its numerically integrated waveform is shown in Fig. 2. The Heidler current waveform and its derivative are shown in Fig. 3. The Spectral Subtraction method is then applied to the distorted Heidler current derivative for de-noising it. Figure 4 presents the simulated (distorted) current derivative and current waveforms, and the de-noised current derivative waveform after the application of the STFT-based Spectral Subtraction method and its numerical integration (the current). The de-noised waveform and its numerical integration proved to be very close to the original Heidler functions. Figure 5 shows a close-in comparison of the de-noised simulated current derivative waveform and the derivative of the Heidler function shown in Fig. 3. The figure demonstrates clearly the great success of the STFT-based Spectral Subtraction method.

\section{SIMULATION RESULTS}

The STFT-based Spectral Subtraction method was applied to the recorded current derivative signal of Fig. 1(a) and it produced the waveform shown in Fig. 6(a) (Fig. 6(b) represents the numerical integration of the de-noised waveform.) When compared with the waveforms of Fig. 1, Fig. 6 demonstrates a substantial success in the removal of the interfering noise.

For the purpose of our studies (accurate determination of waveform parameters), a signal peak-to-noise peak ratio (SPNPR) is proposed. It is defined as the signal peak divided by $50 \%$ of the peak-to-peak noise during the time before the arrival of lightning current return stroke. This ratio theoretically reaches $\infty$ in the absence of noise. The SPNPR both for di/dt and current for the waveforms shown in Fig. 6 is presented in Table I. From the table, the success of the proposed method is clearly demonstrated.

Table I: SPNPR of file G0363096.363

\begin{tabular}{|l|c|c|}
\hline De-Noising & $\boldsymbol{d i} / \boldsymbol{d} \boldsymbol{t}$ & Current (i) \\
\hline Before (measured) & 7.27 & 20.16 \\
\hline After & 151.30 & 361.39 \\
\hline
\end{tabular}

\section{F. Waveform Parameters Calculations}

In order to study the characteristics of lightning impact on tall structures, the waveform parameters of the injected currents to such structures must be determined. In this section, the waveform parameters of both the current derivative (di/dt) and current are obtained from the waveforms after applying the proposed de-noising method.

Several researchers have attempted manually to determine the di/dt and current waveform parameters from noisy waveforms. However, in some cases (e.g. the storm of May 9,2002 ), when the wavefront steepness and peak of the current is considerably low, it becomes extremely difficult to manually determine a reasonable estimate of the current waveform parameters. The proposed de-noising method is applied to lightning return-stroke current derivative signals recorded on May 9, 2002. The obtained waveform parameters are shown in Table II.

\section{CONCLUSIONS}

In this paper, we proposed an STFT-based Spectral Subtraction de-noising algorithm to minimize the effect of the unwanted interferences from the lightning current derivative signals measured at the $\mathrm{CN}$ Tower. We successfully applied the proposed method for de-noising the current derivative signals.

The Heidler function is used to model the lightning current measured at the $\mathrm{CN}$ Tower. The derivative of the Heidler function is artificially distorted by an actual noise signal, measured at the $\mathrm{CN}$ Tower in the absence of lightning. Then the Spectral Subtraction method is used to remove the added noise.

A signal peak-to-noise peak ratio (SPNPR) of the CN Tower lightning current signal is defined and calculated before and after the de-noising process. For example, for a typical measured $\mathrm{CN}$ Tower lightning current derivative signal, the SPNPR before de-noising was found to be 7.27, and after de-noising it became 151.30. Similarly for its current waveform (obtained by numerical integration), the SPNPR before de-noising was 20.16 and it became 361.39 after de-noising.

The current parameters obtained from the de-noised current derivative signals recorded on May 9, 2002 were determined. It is shown that on average, a lightning current waveform has a peak of $7 \mathrm{kA}$ and a maximum wavefront steepness of $16 \mathrm{kA} / \mu \mathrm{s}$ with a risetime to the peak of $3.3 \mu \mathrm{s}$. The use of the proposed de-noising method to accurately extract waveform parameters from the extensive current data recorded at the Tower since 1991 will enable the derivation of valuable statistics. These statistics will assist in designing systems for protection from the hazards of the lightning discharge.

\section{REFERENCES}

[1] M.A. Uman, The Lightning Discharge, Academic Press, Inc., 1987.

[2] A.M. Hussein, W. Janischewskyj, J.S. Chang, V. Shostak, W. Chisholm, P. Dzurevych, and Z.I. Kawasaki, "Simultaneous Measurement of Lightning Parameters for Strokes to the Toronto CN Tower," Journal of Geophysical Research-Atmosphere, vol. 100, no. 5, pp. 8853-8861, May 1995.

[3] W. Janischewskyj, A.M. Hussein, V. Shostak, I. Rusan, J.X. Li and J.S. Chang, "Statistics of Lightning Strikes to the Toronto CN Tower (1978-1995)," IEEE Trans. Power Delivery, vol. 12, no. 3, pp. 1210-1221, July 1997.

[4] A.M. Hussein, W. Janischewskyj, M. Milewski, V. Shostak, J.S. Chang and W. Chisholm, "Return-stroke current waveform characteristics of lightning to the CN Tower (1992-2001)," 
Proceedings of the 26th International Conference on Lightning Protection (ICLP), pp. 161-166, Cracow, Poland, Sept. 2-6, 2002.

[5] M.J. Islam and A.M. Hussein, "Frequency Analysis of CN Tower Lightning Current Signals Using Short Term Fourier Transform", International Conference for Upcoming Engineers (ICUE), Paper\# 2, Maxwell Session, pp. 1-4, Ryerson University, Toronto, Ontario, Canada, May 1 and 2, 2003.

[6] W. Janischewskyj, A.M. Hussein and V. Shostak, "Propagation of Lightning Current within the CN Tower," International Colloquium on Insulation Coordination, CIGRE SC 33.97, Toronto, Ontario, Canada, Sept. 2-3, 1997.

[7] A.K. Ziarani, "Extraction of Non-Stationary Sinusoids," PhD Thesis, Electrical and Computer Engineering, University of Toronto, Toronto, ON, December, 2002.

[8] M.J. Islam and A.M. Hussein, "A Novel Technique for De-Noising the CN Tower Lightning Current Signal by Modifying Its Fast Fourier Transform," International Signal Processing Conference (ISPC), Paper\# 287 (pp. 1-5), Dallas, TX, USA, March 31- April 3, 2003.

[9] S.F. Boll, "Suppression of Acoustic Noise in Speech Using Spectral Subtraction," IEEE Transactions on Acoustics, Speech, and Signal Processing, vol. ASSP-27, no. 2, pp. 113-120, April 1979.

[10] M.J. Islam, "De-Noising the CN Tower Lightning Current Signal Using Short Term Fourier Transform-Based Spectral Subtraction", MASc. Thesis, Electrical and Computer Engineering, Ryerson University, Toronto, Ontario, Canada, October 2003.

[11] S.K. Mitra, Digital Signal Processing: A Computer- Based Approach, Second Edition, New York: McGraw-Hill, 2001.

[12] F. Heidler, "Lightning Electromagnetic Impulse," Theorie und Messungen, Thesis Dissertation, Fakultät der Elektrotechnik, Universität der Bundeswehr, München, 1987.

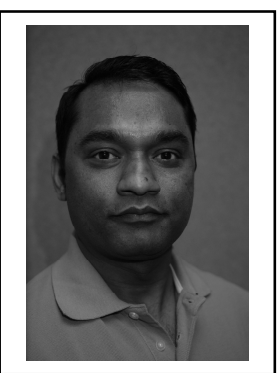

M.J. Islam received the BSc. (Hon's) and MSc. Degree in Electronics and Computer Science in 1995 and 1996 respectively from Shahjalal University of Science and Technology, Sylhet, Bangladesh. He received MASc in Electrical and Computer Engineering from Ryerson University, Toronto, ON, Canada, in 2003. Since 1997, he has been with the Computer Science and Engineering Department at Shahjalal University of Science and Technology, Sylhet, Bangladesh and promoted to Assistant Professor in 2000. Currently he is doing $\mathrm{PhD}$ in Electrical and Computer Engineering at University of Windsor, Windsor, ON, Canada. Mr. Islam has published 2 journal papers and 6 conference papers and received 2 best student paper awards. Mr. Islam is the Professional Engineer (PEng. PEO) in the province of Ontario, Canada. He is also IEEE student member and the member of International Association of Engineers (IAENG). His research interests include but not limited to machine learning and computer vision, image processing and document image analysis.

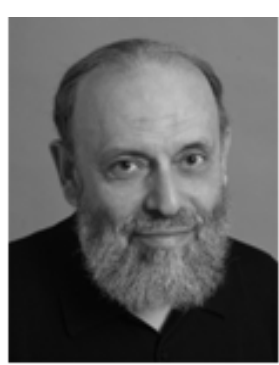

A.M. Hussein received his B.Sc. and M.Sc. degrees from Alexandria University and Ain-Shams University, Egypt, respectively. He received his Ph.D. degree from the University of Toronto in 1979. From 1979 to 1980 , he was a Research Associate at the National Research Council of Canada. From 1980 to 1982, he was an Assistant Professor at the Electrical Engineering Department of Riyadh University. From 1982 to 1986 , he was a Research Associate and lecturer at the Electrical Engineering Department of the University of Toronto. From 1986 to 1988 , he was a Member of the Scientific Staff in the Electromagnetics Technology Division of Bell-Northern Research, Ottawa, Canada. From 1988 to 1989 he was a Visiting Scientist at the Electrical and Computer Engineering Department of the University of Toronto. Since 1989, he has been with the Electrical and Computer Engineering Department of Ryerson University (Professor since 1994) and an Adjunct Professor at the Electrical and Computer Engineering Department of the University of Toronto. Dr. Hussein has authored and co-authored over 150 refereed publications in the areas of Microwave Ferrites, Microwave Acoustics, Non-Destructive Evaluation, Electromagnetic Field Computations, and, more recently, Measurement, characterization and modeling of Fast Transients (Power Line Microgap Discharge, Nuclear-Generated High-Altitude Electromagnetic Pulse, Electrostatic Discharge, and Lightning Discharge).

Table II: Statistics of the waveform parameters

\begin{tabular}{|l|c|c|c|c|c|}
\hline File Name & \multicolumn{1}{|c|}{ Current Derivative $(\boldsymbol{d i} / \boldsymbol{d}$ t) Parameters } & \multicolumn{3}{|c|}{ Current Waveform Parameters } \\
\hline & $\begin{array}{c}\text { Maximum Steepness } \\
(\mathrm{kA} / \mu \mathrm{s})\end{array}$ & $\begin{array}{l}10 \%-90 \% \\
\text { Risetime }(\mu \mathrm{s})\end{array}$ & $\begin{array}{c}\text { First Peak } \\
(\mathrm{kA})\end{array}$ & $\begin{array}{c}10 \%-90 \% \\
\text { Risetime }(\mu \mathrm{s})\end{array}$ & $\begin{array}{c}\text { Absolute Peak } \\
(\mathrm{kA})\end{array}$ \\
\hline E0909244.931 & 20.55 & 0.39 & 5.92 & 0.97 & 6.81 \\
\hline E0909245.022 & 19.78 & 0.66 & 6.92 & 0.65 & 7.51 \\
\hline E0909245.073 & 24.59 & 0.13 & 5.71 & 5.16 & 6.21 \\
\hline E0909245.234 & 18.62 & 0.41 & 8.65 & 5.05 & 9.57 \\
\hline E0909245.496 & 19.02 & 0.53 & 3.68 & 0.62 & 4.26 \\
\hline E0909702.021 & 4.60 & 2.54 & 14.80 & 4.95 & 15.91 \\
\hline E0909705.211 & 3.47 & 0.44 & 4.12 & 5.66 & 4.21 \\
\hline Average & 15.80 & 0.73 & 7.12 & 3.30 & 7.78 \\
\hline
\end{tabular}



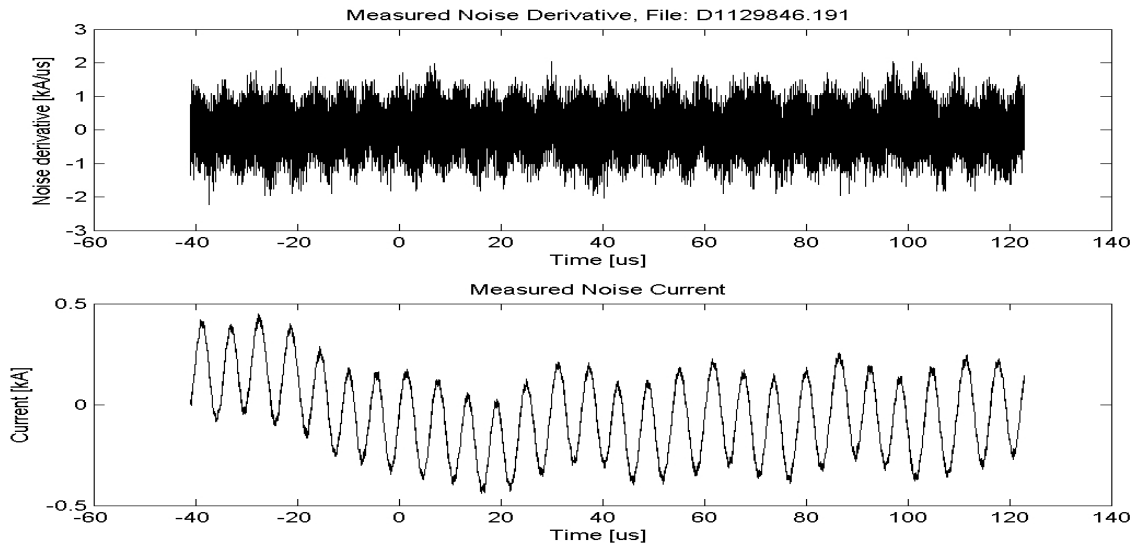

Fig. 2: Measured noise derivative and noise waveform.
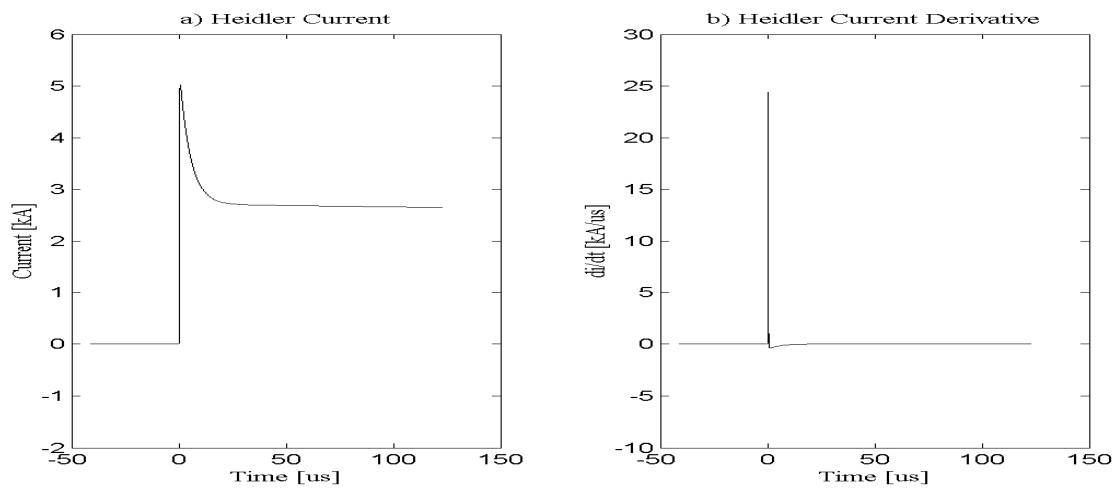

Fig. 3: A Heidler current waveform and its derivative.
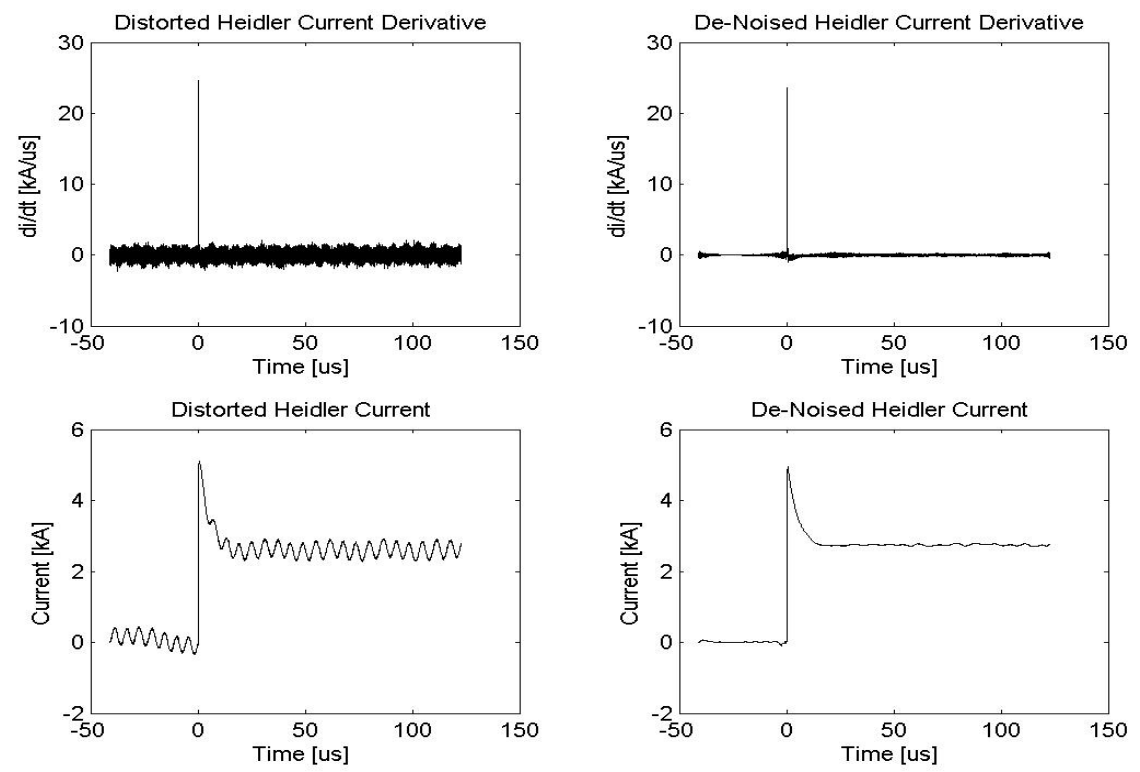

Fig. 4: Comparison of distorted Heidler current derivative and current before and after the de-noising process. 


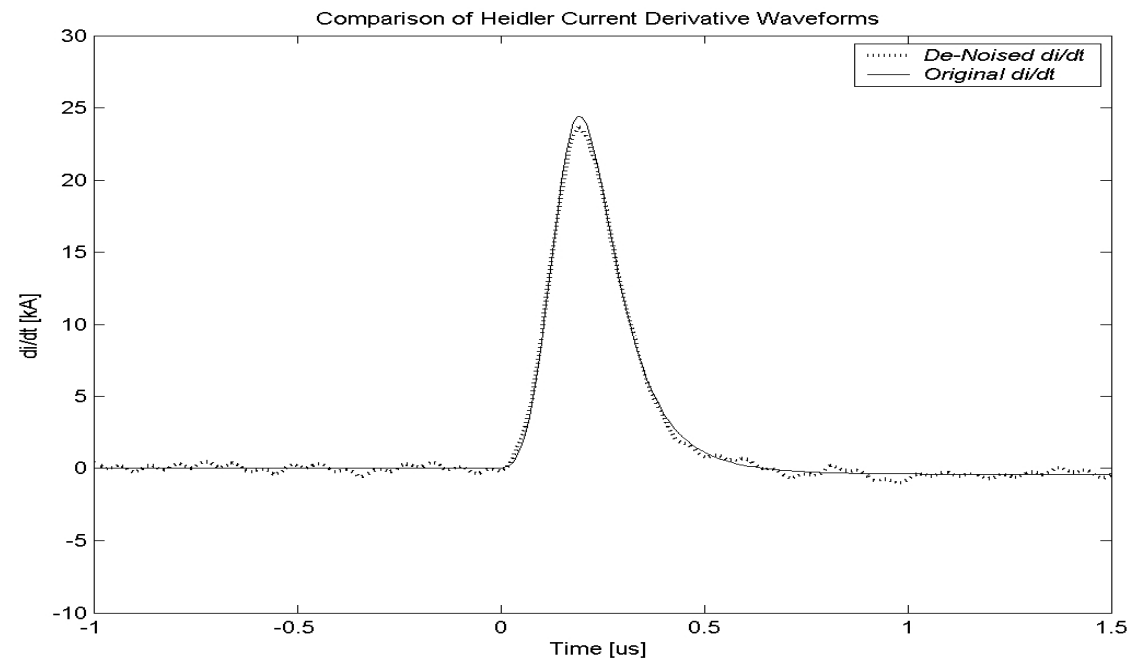

Fig. 5: Close-in comparison of the de-noised simulated current derivative and the derivative of the Heidler function.
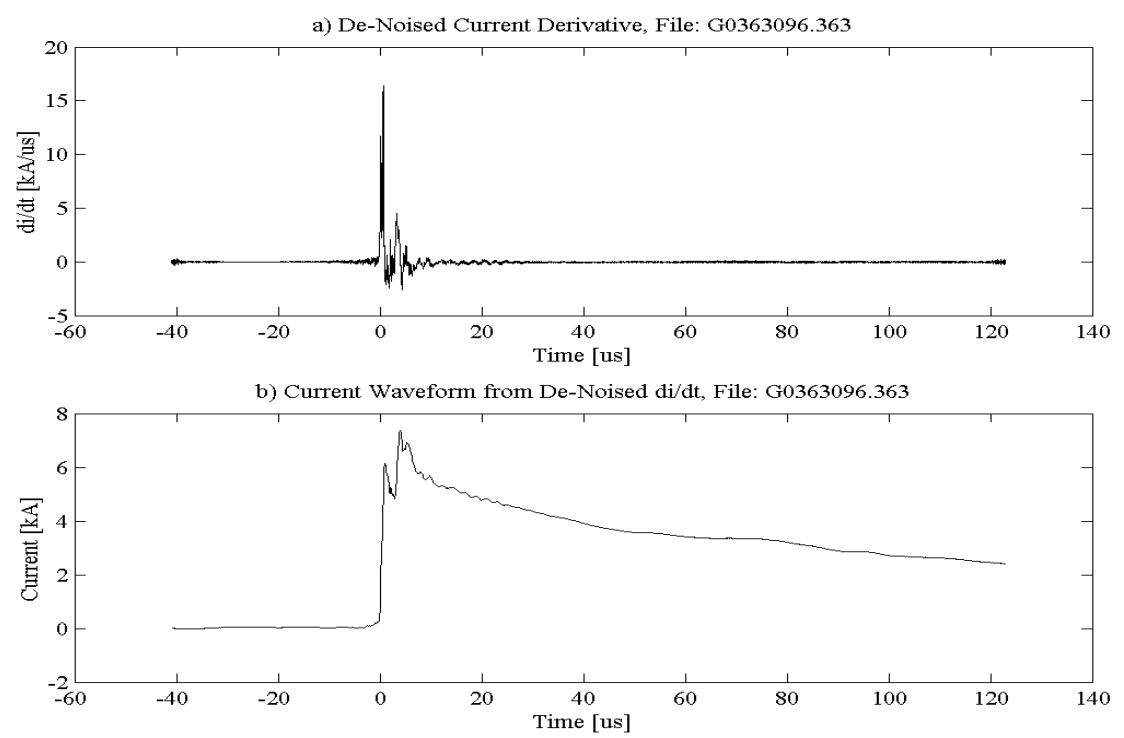

Fig. 6: De-noised current derivative waveform and its numerical integration (the current). 